\title{
Assessment of the Entropy of Spatial and Time Distributions of Rooms Daylighting: A Possible Tool for a Sustainable Design
}

\author{
Alessandra Galatioto" ${ }^{* 1}$,Marco Beccali ${ }^{2}$ \\ ${ }^{1}$ DEIM-Dipartimento dell'Energia dell'Ingegneria dell'informazione e dei Modelli matematici \\ Università degli Studi di Palermo, Viale delle Sicenze, bldg 9, 90128 Palermo, Italy \\ e-mail: alessandra.galatioto@dream.unipa.it \\ ${ }^{2}$ DEIM-Dipartimento dell'Energia dell'Ingegneria dell'informazione e dei Modelli matematici \\ Università degli Studi di Palermo, Viale delle Sicenze, bldg 9, 90128 Palermo, Italy \\ e-mail: marco.beccali@dream.unipa.it
} 2015, DOI: http://dx.doi.org/10.13044/j.sdewes.2015.03.0032

\begin{abstract}
The indoor visual comfort of subjects faced with indoor ambient lighting varies with the position of the subject and is not constant over time. Average performance indexes, such as the mean value of Daylight Factor and Daylight Autonomy, are commonly used to analyse lighting distribution. These indexes, however, don't properly take into account either the spatial or the time distribution of values affecting the non-uniformity of environmental lighting. Indeed, these are limited to the definition of a mean value or to the assessment of time availability of daylighting. This paper examines spatial and temporal non-uniformities in indoor lighting as possible causes of discomfort for occupants. The goal is to propose and verify possible supplementary tools to integrate traditional methods of evaluating ambient indoor lighting. Use of the entropy theory with a probabilistic approach can help to obtain more detailed information about the environment. The authors have developed a case study of several sample environments and have analysed the relationships between lighting parameters and typical indices of information theory. Results show that this approach could be a useful way for predicting possible indoor visual comfort issues and for developing a preliminary assessment to a sustainable building design.
\end{abstract}

\section{KEYWORDS}

Information theory, Visual comfort, Daylight factor, Daylight autonomy, Lecture halls.

\section{INTRODUCTION}

A proper lighting design that will ensure comfort for visual tasks must focus on the appropriate ambient lighting distribution. The most used parameters in lighting design practice are often too generic to give useful description of environmental lighting conditions and the ensuing result might not be satisfactory. The purpose of this research is to critically evaluate some common rapid methods for analysing environmental lighting conditions and to provide a new possible analytical approach. This research considers daylight illuminance data but does not take into account glare. The evaluation of ambient lighting is often made through an overall assessment of the environment.

An important aspect of visual comfort is the correct use of daylight. Defining and assessing visual comfort in daylight ambient deals with many variables. Some of them depend on climate aspects, such as the daylight availability over the time or sky

\footnotetext{
* Corresponding author
} 
luminance, while other are related to room geometry and material properties: number, orientation and dimensions of windows, shading devices, optical characteristics of surfaces.

The natural lighting performance index evaluates and classifies lighting environment conditions while taking into account relative illuminance, but the index often does not provide a complete description of the indoor lighting characteristics.

For instance, a strong spatial non-uniformity of the illuminance levels is often considered a negative characteristic. The higher the variability in this parameter the higher the need will be for subjects to adapt to different conditions [1,2].

Real daylight illuminances in buildings change more than is suggested by variations in predicted Daylight Factor (DF). The conventional approach produces a single number - the Daylight Factor as a percentage - for each evaluation point in the space. Notions of illuminance uniformity that are a legacy of the traditional Daylight Factor approach are therefore inapplicable for realistic daylight conditions [3].

Furthermore, the well-known Daylight Factor has other limitations. It does not provide information about actual sky luminance conditions because it refers to the CIE standard sky conditions and presents difficulties in coordinating external and internal measures. Also, it cannot be used as an indicator of the levels of illumination provided by a combination of natural and artificial light and it doesn't provide information about the glare from natural light and generally in the indoor lighting assessment, the DF standardizes very different "lighting zones", even within the same space and visual task [4].

In 1989, the "Association Suisse des Electriciens" proposed the Daylight Autonomy (DA) parameter, developed by C. Reinhart from 2001 to 2004 [5]. It was the first dynamic approach for daylighting indoor evaluation. DA represents the percentage of hours during the year, in which the illuminance values are above a predefined threshold. DA measures the percentage of how often the illumination due only to daylight exceeds a set illumination threshold over a given period of time.

DA parameter doesn't provide relevance either to lighting values below the established lighting threshold or to the ones above it. This approach cannot be suitable to predict possible visual discomfort phenomena. Reinhart et al. defined several new dynamic performance indices according to the Climate-based Daylight Modelling (CBDM). CBDM predicts various radiant or luminous conditions using sun and sky data derived from standard meteorological datasets [6-8]. However, these analysis methods give information about the daylight availability, but do not give any information about the illuminance distribution values [9].

\section{THE ENTROPIC-PROBABILISTIC APPROACH AND INFORMATION THEORY METRIC TO LIGHTING ASSESSMENT}

In information theory, entropy is used to measure the amount of uncertainty in the information that is present in a random signal [10]. The Shannon approach involves the treatment of entropy as a characteristic of the status of a system, similar to its role in thermodynamics. In information theory, entropy means that the information of a message can never rise above the value it had at the time of transmission, but the value may decrease because of deterioration processes. The application of the information theory to different fields is well known and consolidated [11]. The basic problem of all applications concerns the comparison, analysis and interpretation of the results. In this way, a very interesting method has been proposed by Mahdavi and Pal, who introduced a new index called EDI [12]. Authors demonstrated potentiality of an entropy-based measure of light distribution. EDI aims to characterize certain range of values, in order to 
define the lighting conditions and improve visual performance of the occupants. Despite EDI solves the issues related to uniformity distribution analysis, any information has been provided about time distribution of values. The authors, in the present work, liken the lighting distribution inside a space to a deterministic signal that is to be predicted at any time and place by the receiver (the light user or room occupant). In an environment where the signal is uniform (i.e., the signal is noise-free), the entropy of the transmitted message is equal to the entropy of the source message so that entropy is minimised and the message interpretation is unique and reliable [13-16]. Indeed, every real system is permeated by "noise", which substantially contributes to the ambiguity of the source according to the receiver's interpretation. An analysis of a data series (signals) can be developed through the study of the distribution of its values by the well-known Shannon-Wiever equation (1):

$$
H=\sum_{i=1}^{n} P_{i} \ln \left(P_{i}\right)
$$

where $H$ is the entropy of the series, $P_{i}$ is the probability of the i-th signal and $\ln$ is the natural logarithm. Entropy information is connected to this probability in the same way in which entropy in thermodynamics is connected to the probability of the system state: each real transformation of the system implies a rise in its entropy. In information theory, transmission of a signal is considered a transformation.

The parameter used for assessing the disorder of the transmission process is the ratio $H / H_{\max }$, also known as "noise", where $H$ is the entropy of the system and $H_{\max }$ is the maximum entropy that the system would have if all the signals had the same probability of occurrence. Another parameter that can be used is the Redundancy, $R$, which is defined as the complement to 1 of the $H / H_{\max }$ ratio, i.e., $R=1-H / H_{\max }$. Thus, a totally random source has $H / H_{\max }=1$ and $R=0$, while a "uniform" source that has all the signals equal to each other has $H / H_{\max }=0$ and $R=1$.

If the lack of lighting uniformity in a room is considered a weakness, the quality of the space can be investigated through this type of analysis. By this approach, the internal environment is analysed as the signal source, while the subject is the receiver. Table 1 summarises the scheme for the calculation of $P_{i}, H, H_{\max }$.

Table 1. Entropy calculation matrix

\begin{tabular}{|c|c|c|c|c|c|c|}
\hline & A & A-B & B-C & C-D & $\mathrm{Y}-\mathrm{Z}$ & $\Sigma$ \\
\hline$\alpha$ & $\alpha<\mathrm{A} ; \alpha \geq \mathrm{B}$ & $\alpha<\mathrm{A} ; \alpha=\mathrm{B}$ & $\alpha<\mathrm{C} ; \alpha \geq \mathrm{D}$ & $\alpha<\mathrm{D} ; \alpha \geq \ldots$ & $\alpha<\ldots ; \alpha \geq Z$ & 1 \\
\hline$\beta$ & $\beta<\mathrm{A} ; \beta \geq \mathrm{B}$ & $\beta<\mathrm{B} ; \beta \geq \mathrm{C}$ & $\beta<\mathrm{C} ; \beta \geq \mathrm{D}$ & $\beta<D ; \beta \geq \ldots$ & $\beta<\ldots ; \beta=Z$ & 1 \\
\hline$\gamma$ & $\gamma<\mathrm{A} ; \gamma \geq \mathrm{B}$ & $\gamma<\mathrm{B} ; \gamma \geq \mathrm{C}$ & $\gamma<\mathrm{C} ; \gamma \geq \mathrm{D}$ & $\gamma<\mathrm{D} ; \gamma \geq \ldots$ & $\gamma<\ldots ; \gamma \geq Z$ & 1 \\
\hline$\delta$ & $\delta<\mathrm{A} ; \delta \geq \mathrm{B}$ & $\delta<\mathrm{B} ; \delta \geq \mathrm{C}$ & $\delta<\mathrm{C} ; \delta \geq \mathrm{D}$ & $\delta<\mathrm{D} ; \delta \geq \ldots$ & $\delta<\ldots ; \delta=\mathrm{Z}$ & 1 \\
\hline$n_{i}$ & $n(\mathrm{~A})$ & $n(\mathrm{~A}-\mathrm{B})$ & $n(\mathrm{~B}-\mathrm{C})$ & $n(\mathrm{C}-\mathrm{D})$ & $n(\mathrm{Y}-\mathrm{Z})$ & $n_{\text {ТОт }}$ \\
\hline \multirow{4}{*}{$P_{i}$} & $n(\mathrm{~A})$ & $n(\mathrm{~A}-\mathrm{B})$ & $n(\mathrm{~B}-\mathrm{C})$ & $n(\mathrm{C}-\mathrm{D})$ & $n(\mathrm{Y}-\mathrm{Z})$ & $100 \%$ \\
\hline & $n_{\text {тот }}$ & $n_{\text {тот }}$ & $n_{\text {тот }}$ & $n_{\text {тот }}$ & $n_{\text {тот }}$ & $100 \%$ \\
\hline & $p_{i_{(\mathrm{A})}} \log p_{i_{(\mathrm{A})}}$ & $p_{i_{(\mathrm{A}-\mathrm{B})}} \log p_{i_{(\mathrm{A}-\mathrm{B})}}$ & $p_{i_{(\mathrm{B}-\mathrm{C})}} \log p_{i_{(\mathrm{B}-\mathrm{C})}}$ & $p_{i_{(\mathrm{C}-\mathrm{D})}} \log p_{i_{(\mathrm{C}-\mathrm{D})}}$ & $p_{i_{(\mathrm{Y}-\mathrm{Z})}} \log p_{i_{(\mathrm{Y}-\mathrm{Z})}}$ & $H$ \\
\hline & & & $\frac{n_{\text {тот }}}{N}$ & & & $H_{\max }$ \\
\hline
\end{tabular}

where:

- $\quad \alpha, \beta, v, \delta$ are four possible values of the variable under examination; 
- $\mathrm{A}, \mathrm{B}=(\mathrm{A}-\Delta x), \mathrm{C}=(\mathrm{B}-\Delta x)$, etc...: are the boundaries of the range of the intervals used to calculate the probabilities with $\Delta x$ being the amplitude of the $\mathrm{n}$-th interval.

In Figure 1, three different lighting distributions in a simple square room are represented. The first one is referred to a totally uniform lighting environment, with a constant value of $50 \mathrm{~lx}$ in all the grid points. The second one represents a possible example of non uniformity, mainly occurring along one dimension of the room. The last one is representative of an almost random distribution. It can be noticed that the "disorder" of the lighting environment rises from case 1 to case 2 and then 3 . The calculated values of $H / H \max$ and $R$ that describe the status of the system are also shown in Figure 1. It can be noted (Calculation 1) that the higher spatial non-uniformity the higher $H / H_{\max }$, it being a measure of disorder. This example shows how such index can be utilised for a measure of the uniformities of lighting. The same approach can be adopted for the analysis of time series of illuminance for a given point in order to assess the way the illuminance changes during time (constant, gradual, random).
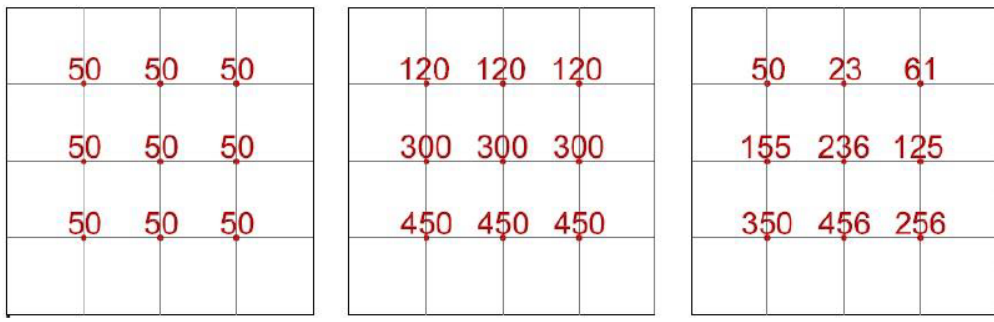

Calculation 1)

\begin{tabular}{cc}
\hline \multicolumn{3}{c}{ Scene 1} \\
\hline $\mathrm{H}_{\max }$ & 4.0 \\
$\mathrm{H}$ & 0 \\
$\mathrm{H} / \mathrm{H}_{\max }$ & 0 \\
$\Delta \mathrm{x}$ & $25 \mathrm{~lx}$ \\
$\mathrm{Pi}$ & $1 / 16$ \\
$\mathrm{R}$ & 1 \\
\hline Calculation 2) \\
\hline \multicolumn{2}{c}{ Scene 1} \\
\hline $\mathrm{H}_{\max }$ & 3.3 \\
$\mathrm{H}$ & 0 \\
$\mathrm{H} / \mathrm{H}_{\max }$ & 0 \\
$\Delta \mathrm{x}$ & $25 \mathrm{~lx}$ \\
$\mathrm{Pi}$ & $1 / 10$ \\
$\mathrm{R}$ & 1 \\
\hline
\end{tabular}

\begin{tabular}{cc}
\hline \multicolumn{2}{c}{ Scene 2} \\
\hline $\mathrm{H}_{\max }$ & 4.0 \\
$\mathrm{H}$ & 1.05 \\
$\mathrm{H} / \mathrm{H}_{\max }$ & 0.26 \\
$\Delta \mathrm{x}$ & $25 \mathrm{~lx}$ \\
$\mathrm{Pi}$ & $1 / 16$ \\
$\mathrm{R}$ & 0.73 \\
\hline \multicolumn{2}{c}{} \\
\hline \multicolumn{2}{c}{ Scene 2} \\
\hline $\mathrm{H}_{\max }$ & 3.3 \\
$\mathrm{H}$ & 1.05 \\
$\mathrm{H} / \mathrm{H}_{\max }$ & 0.31 \\
$\Delta \mathrm{x}$ & $25 \mathrm{l}$ \\
$\mathrm{Pi}$ & $1 / 10$ \\
$\mathrm{R}$ & 0.68 \\
\hline
\end{tabular}

\begin{tabular}{cc}
\hline \multicolumn{2}{c}{ Scene 3 } \\
\hline $\mathrm{H}_{\max }$ & 4.0 \\
$\mathrm{H}$ & 1.18 \\
$\mathrm{H} / \mathrm{H}_{\max }$ & 0.29 \\
$\Delta \mathrm{x}$ & $25 \mathrm{~lx}$ \\
$\mathrm{Pi}$ & $1 / 16$ \\
$\mathrm{R}$ & 0.70 \\
\hline \multicolumn{2}{c}{} \\
\hline \multicolumn{2}{c}{ Scene 3} \\
\hline $\mathrm{H}_{\max }$ & 3.3 \\
$\mathrm{H}$ & 1.65 \\
$\mathrm{H} / \mathrm{H}_{\max }$ & 0.49 \\
$\Delta \mathrm{x}$ & $25 \mathrm{x}$ \\
$P i$ & $1 / 10$ \\
$\mathrm{R}$ & 0.50 \\
\hline
\end{tabular}

Figure 1. Different lighting distributions in a three status of the sample square room and comparison between two calculations with different $P_{i}$

However, it is necessary to underline that in order to calculate $H$ and $H_{\max }$ for a given series of values it is necessary to set the number of intervals of illuminance in order to account for the probability $p_{i}$ of occurrences within the intervals. With the aim to show the influence of the choice of this number for a given set of data, we have performed two different calculations. In a first analysis (Calculation 1) a number of 16 intervals have been set. The number of intervals with fixed amplitude $(\Delta x)$ of $25 \mathrm{~lx}$ can be calculated by taking into account the maximum and minimum values of the signals. In the three cases the $H / H_{\max }$ figures will be $0,1.05$ and 1.18 .

If we change the number of intervals from 16 to 10 (Calculation 2), the interval amplitude will be $25 \mathrm{~lx}$ and the calculated values of $H / H_{\max }$ will be $0,1.05$ and 1.65 for three cases. It must be highlighted that the null value of $H / H_{\max }$ is always representative 
of homogeneous distributions, while the highest value is representative of the most disordered space. Moreover, the choice of the number of intervals or its amplitude is arbitrary and affects the values of $H$ and $H / H_{\max }$. The higher the amplitude, the lower is the $H / H_{\max }$ value. Anyway being the trend between $H / H_{\max }$ and the measure of the disorder always consistent, if the same $\Delta x$ are adopted for all the cases being analysed, the comparison will be meaningful, as demonstrated by Barbera and Butera [17].

In this work, the authors have applied this tool to analyse the lighting of an indoor environment by two points of view: the way in which the light is distributed in a room (spatial analysis) and the way in which the light changes over time upon a given point (time analysis). Illuminance data series values are examined according to the above mentioned approach (Table 1).

\section{Case study development, analysis of time distribution through information theory metric}

The proposed case study is the lecture hall of the Faculty of Architecture of University of Palermo. In this ambient there are many lecturing tables and computer workstations. The lecture hall has regular shape and wide glass surface, shaded by user-operable internal and external louvers. Twelve workstations have been analysed:

- 10 rectangular desks with 6 workstations;

- 1 square desk with 4 workstations;

- 1 round desk with 4 workstations.

Three illuminance values on each workplace have been measured with a luxmeter (GOSSEN" ${ }^{\text {TM }}$ Mavolux 5032B-USB; Admissible deviation: \pm 0.1 lx for 0.0 lx Test point, $\pm 3.0 \mathrm{~lx}$ for $190.0 \mathrm{~lx}$ Test point) for a total of 36 points. The average value for each workstation was used to calculate the DF value for the workstations.

In Figure 2 the layout of the room is represented and the average $1 \mathrm{x}$ values measured on the tables are also reported. The authors generated several data sets for the same case study in order to calculate the proposed performance indexes at different latitudes: Palermo (Lat: $38.2^{\circ}$, Lng: $13.1^{\circ}$ ), Rome (Lat: 41.8 ${ }^{\circ}$; Lng: $12.06^{\circ}$ ) and Milan (Lat: $45.4^{\circ}$; Lng: $9.03^{\circ}$ ), but not changing the room orientation.

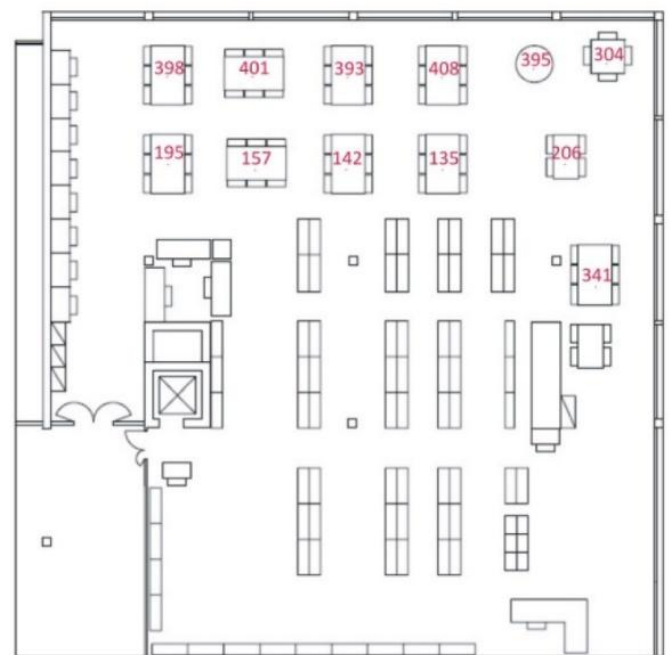

Figure 2. Plan of the library and workstations position

A preliminary calculation of Daylight Factor [\%] for the entire room has been performed through Daysim and Autodesk Ecotect Analysis software [18, 19]. The simulations have been performed without curtains, in order to verify the real solar 
radiation contribution on the surface. Figure 3 shows the DF mapping for Palermo latitude. As it can be noticed, very high DF values are registered due to the large window area. The $\mathrm{DF}_{\mathrm{avg}}$ value is $\sim 15.0 \%$, which is considered an acceptable value for most occupation patterns.
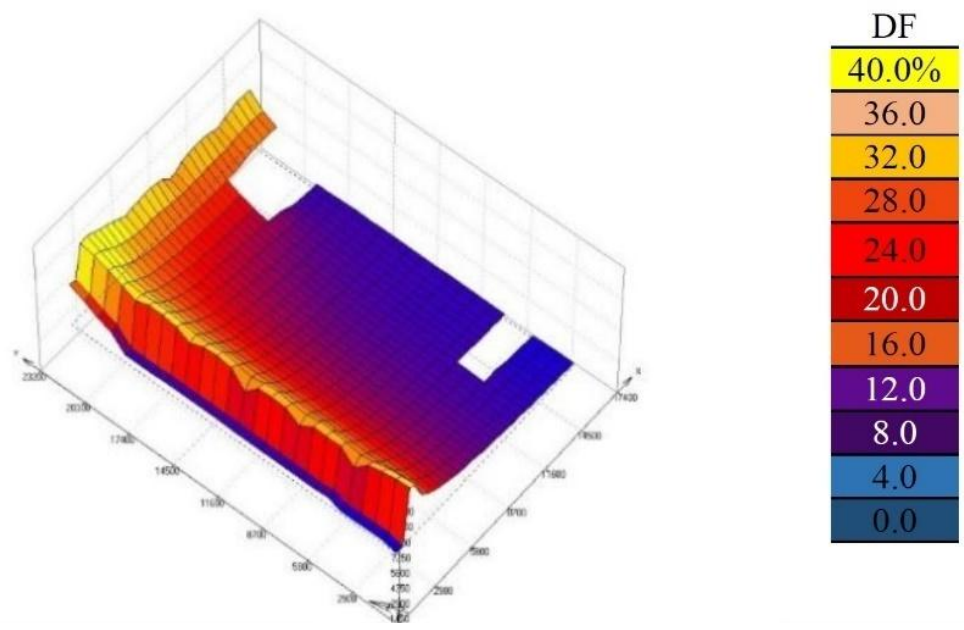

Figure 3. Lecture hall, DF mapping Latitude of Palermo

Figure 4 shows DA values plots at the three latitudes. As it can be observed the daylight autonomy occurs for more than $93 \%$ of the time, a value that is considered acceptable.
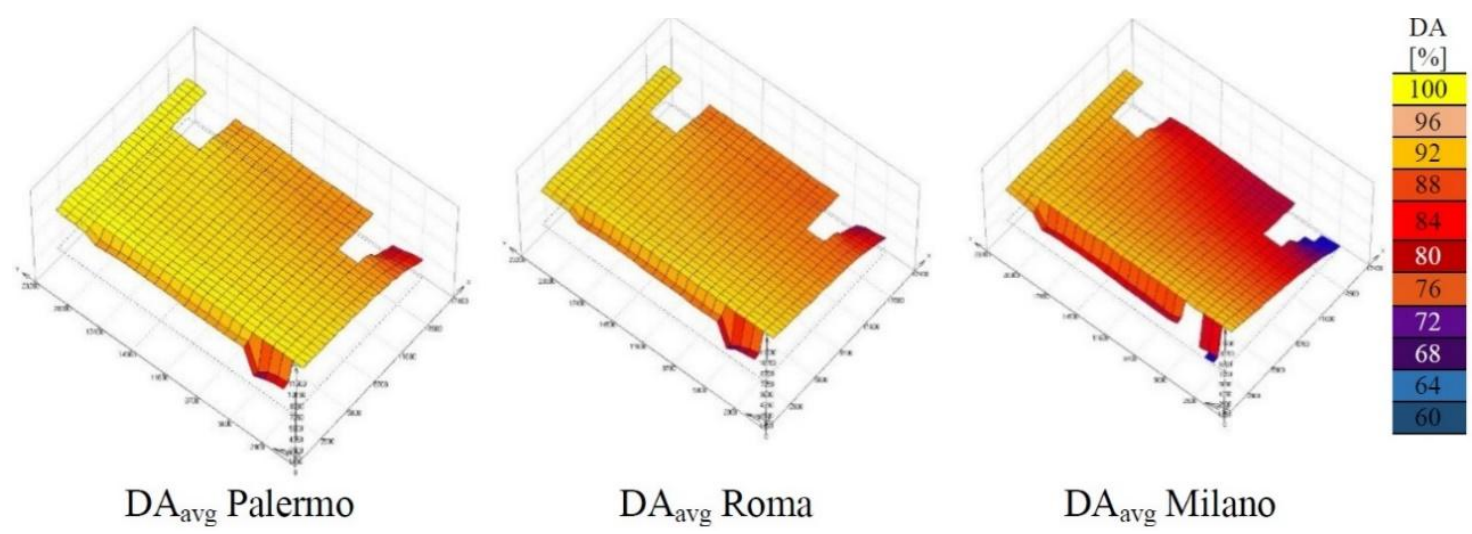

Figure 4. DA index mapping at different proposed Latitudes

According to the preliminary results the indoor visual conditions can be considered "comfortable" for the given visual task performance.

\section{Analysis of time distribution through information theory metric}

The entropic-probabilistic approach was also used to analyse the time variation of the illuminance upon a given point. While the DF values were intrinsically constant over time, $H / H_{\max }$ could assess how the illuminance values changed with the external values.

Additional simulations were carried out for the assessment of time distribution, on each workstation in the room. The analysis was conducted on a sample of 131,400 data values (3,650 data samples for each workstation). The simulations were carried out using real sky conditions during the operational hours of the room between the hours of 9:00 and 17:00. 
The calculation grids were restricted to a $0.25 \times 0.25 \mathrm{~m}$ mesh displaced to given workstation surfaces, and the mean value has been evaluated. For each workstation the $\mathrm{DA}_{\text {avg }}, \mathrm{DF}_{\text {avg }}$ ratio and $H / H_{\text {max } t}$ (where the index $t$ stands for time) parameters have been calculated. In Table 2 the calculated indexes $\mathrm{DF}_{\text {avg }}, \mathrm{DA}_{\text {avg }}$ and $H / H_{\text {max }-t}$ parameter are reported in Table 2. Furthermore, $H / H_{\text {max- } t}$ has been reported for each time series in all considered latitude calculations.

Table 2. Time analysis data report in the lecture hall

\begin{tabular}{|c|c|c|c|c|c|c|c|c|c|c|c|c|}
\hline Table & & $\begin{array}{c}\mathrm{DF}_{\text {avg }} \\
{[\%]}\end{array}$ & $\begin{array}{c}\mathrm{DA}_{\text {avg }} \\
{[\%]}\end{array}$ & $H / H_{\max -t}$ & & $\begin{array}{c}\mathrm{DF}_{\text {avg }} \\
{[\%]}\end{array}$ & $\begin{array}{c}\mathrm{DA}_{\text {avg }} \\
{[\%]}\end{array}$ & $H / H_{\max -t}$ & & $\begin{array}{c}\mathrm{DF}_{\text {avg }} \\
{[\%]}\end{array}$ & $\begin{array}{c}\mathrm{DA}_{\text {avg }} \\
{[\%]}\end{array}$ & $H / H_{\text {max }-t}$ \\
\hline A & \multirow{12}{*}{ 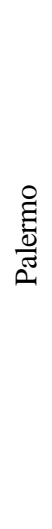 } & 14,0 & 96 & 0,92 & \multirow{12}{*}{$\begin{array}{l}\stackrel{0}{0} \\
\stackrel{0}{2}\end{array}$} & 14,0 & 91 & 0,82 & \multirow{12}{*}{ 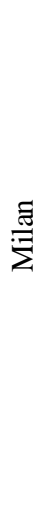 } & 14,7 & 95 & 0,71 \\
\hline B & & 10,0 & 92 & 0,84 & & 10,0 & 94 & 0,94 & & 10,1 & 84 & 0,88 \\
\hline C & & 13,0 & 94 & 0,92 & & 13,0 & 91 & 0,90 & & 13,1 & 95 & 0,82 \\
\hline D & & 10,0 & 93 & 0,83 & & 10,0 & 94 & 0,95 & & 10,3 & 85 & 0,89 \\
\hline E & & 15,0 & 95 & 0,91 & & 15,0 & 92 & 0,80 & & 15,1 & 91 & 0,68 \\
\hline $\mathrm{F}$ & & 10,5 & 93 & 0,85 & & 10,5 & 96 & 0,96 & & 10,7 & 86 & 0,90 \\
\hline G & & 16,0 & 97 & 0,87 & & 16,0 & 95 & 0,75 & & 16,1 & 91 & 0,62 \\
\hline $\mathrm{H}$ & & 11,7 & 94 & 0,88 & & 11,7 & 95 & 0,96 & & 11,6 & 89 & 0,92 \\
\hline I & & 22,6 & 100 & 0,49 & & 22,6 & 96 & 0,50 & & 22,3 & 93 & 0,35 \\
\hline $\mathrm{L}$ & & 17,9 & 98 & 0,74 & & 17,9 & 95 & 0,61 & & 19,0 & 92 & 0,47 \\
\hline M & & 12,7 & 95 & 0,90 & & 12,7 & 94 & 0,93 & & 12,5 & 90 & 0,86 \\
\hline $\mathrm{N}$ & & 14,9 & 96 & 0,91 & & 14,9 & 95 & 0,81 & & 14,9 & 92 & 0,69 \\
\hline
\end{tabular}

For the latitude of Palermo, Figure 5 shows a good correlation $\left(R^{2}=0.949\right)$ between $\mathrm{DA}_{\text {avg }}$ and $\mathrm{DF}_{\mathrm{avg}}$ ratio for each workstation, and it is clear that the higher the $\mathrm{DF}_{\mathrm{avg}}$ the higher the $\mathrm{DA}_{\text {avg }}$.

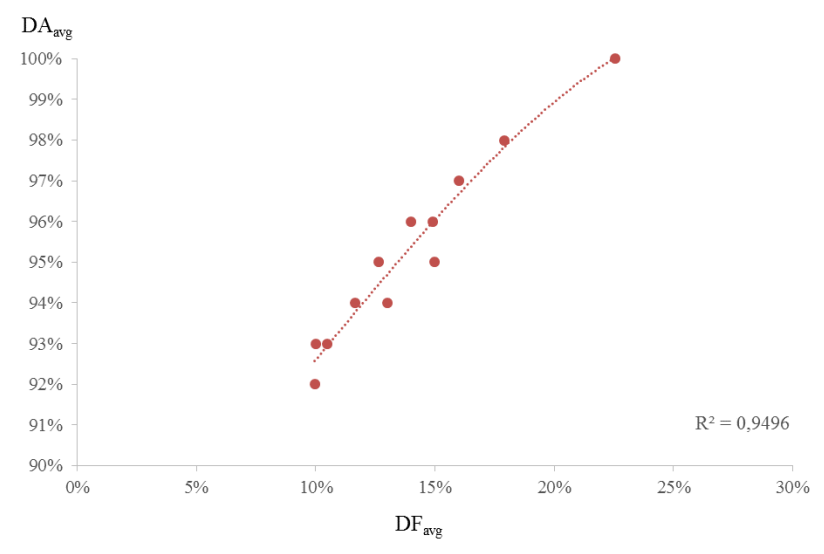

Figure 5. Correlation between $\mathrm{DA}_{\text {avg }}$ and $\mathrm{DF}_{\text {avg }}$ indices in the case of Palermo

Furthermore, the correlation between $\mathrm{DF}_{\text {avg }}$ and $H / H_{\max }$ ratio have been analysed in all proposed latitudes. The results suggest a different point of view in the lighting analysis of rooms. Although higher DF usually take higher DA values, potential unfair effects arose. This is highlighted by the $H / H_{\max }$ index representing "the level of disorder". In other words, the occurrence of time series with increasing spreads among the population of data associated to certain values of DF. Diagrams in Figure 6-8 show these unexpected effects. In fact, it can be noted that the maximum disorder in time distributions (highest values of $H / H_{\text {max }-t}$ ) is correspondent to a thresholds value of $\mathrm{DF}_{\text {avg }}$ (about $12 \%$ for all the three locations). 


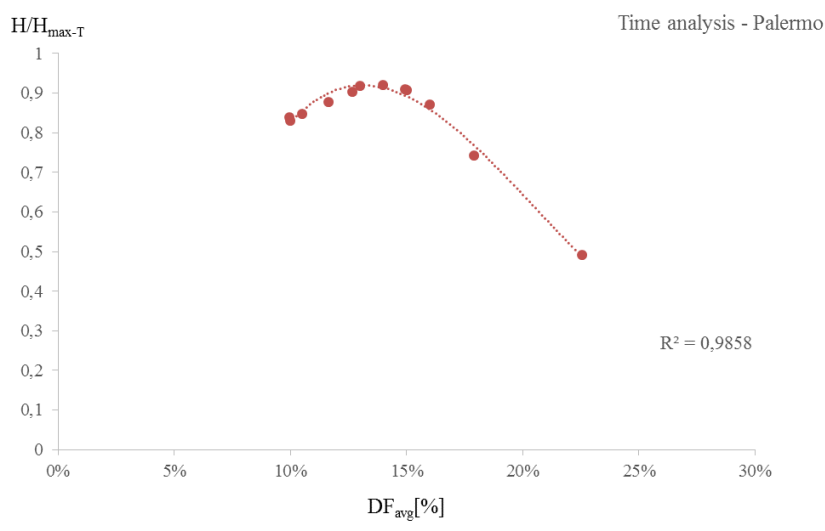

Figure 6. Time analysis, correlation between $H / H_{\text {max }-t}$ and $\mathrm{DF}_{\text {avg }}$ in all Tables Latitude of Palermo

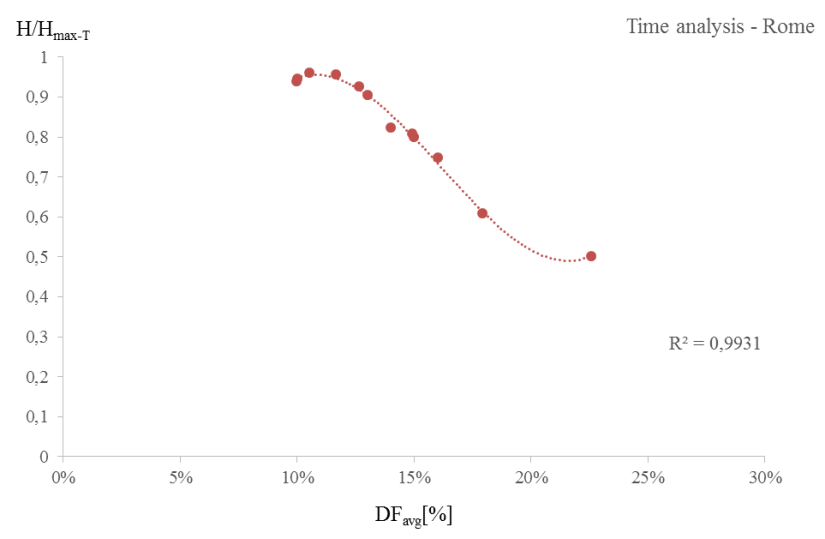

Figure 7. Time analysis, correlation between $H / H_{\text {max }-t}$ and $\mathrm{DF}_{\text {avg }}$ in all Tables Latitude of Rome

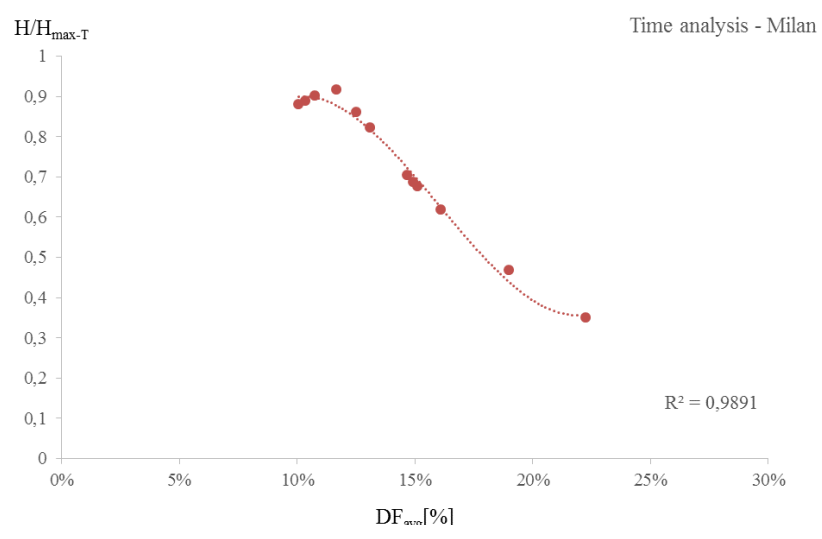

Figure 8. Time analysis, correlation between $H / H_{\text {max }-t}$ and $\mathrm{DF}_{\text {avg }}$ in all Tables Latitude of Milan

The trends of all proposed correlations are very similar: there is a peculiar value of $\mathrm{DF}_{\mathrm{avg}}$ where the $H / H_{\max }$ maximum value occurs, $\mathrm{DF}_{\mathrm{avg}} \sim 12.0 \% ; H / H_{\max } \sim 0.9$. Also, the trend shows aminimum value of $H / H_{\max }$ with a $\mathrm{DF}_{\mathrm{avg}} \sim 20 \%$. This is due to the good uniformity of the time series for the highest illuminance values. If this fact is confirmed by other case studies, it will imply that there are two intervals of DF which must be 
considered in lighting design. In the first interval, although DA increases together with $\mathrm{DF}$, a potential discomfort due to higher variations of illuminance during time can be expected. Its left boundary is DF $=0$, while the right one is the "threshold value". A second interval is included between this last value and a second critical DF value (in this case about 20\%). It occurs that the higher the DF the higher the DA (as usual) the lower the $H / H_{\max }$ (let's say the lower the potential discomfort).

In terms of design, this result suggests:

- Relatively low values of DF which comply with minimum daylight requirements and ensure good DA values are acceptable also for the task of limiting potential discomfort;

- There is a range of DF values that, although providing good levels of illuminance and good DA values, can potentially maximize discomfort due to non-uniformity;

- High DF values can ensure high DA values and, at the same time, can limit the risk of discomfort due to non-uniformity. Anyway, it is well known that "excessive levels of daylight are associated with occupant glare discomfort and unwanted solar gain" [20].

In this way, the $H / H_{\max }$ calculation can be utilized as a supplementary tool for the lighting analysis.

\section{CONCLUSION}

The paper presents a method aimed to analyse the spatial and time variability of natural illuminance levels in indoor spaces by the use of an entropic-probabilistic approach. A comparison between DF, DA and typical indexes of information theory metric, usually applied to signal-source interaction analysis, has been presented. The results suggest some considerations. First of all, in the investigated spaces good correlations have been found between the $\mathrm{DF}_{\text {avg }}$ and the entropy ratio $H / H_{\max }$ (for time distributions) calculated for the values of illuminances at several points on workstations. These correlations proved to be stronger for time series than for space distributions. Moreover, in the analysis of spatial distribution, the better correlations are associated with data series for specific visual task areas (workstations). Data series analysis has highlighted that a critical value of $\mathrm{DF}_{\mathrm{avg}}$ is associated to high levels of non-uniformity.

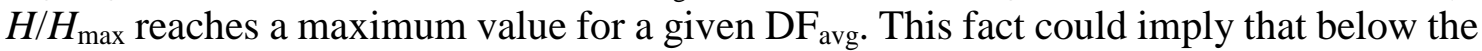
threshold value of $\mathrm{DF}_{\mathrm{avg}}$, the higher the $\mathrm{DF}_{\mathrm{avg}}$ in a given area the higher the "noise" associated with the distribution of the values. The same considerations can be made for the relationships between DA and $H / H_{\max }$. Over this threshold value $H / H_{\max }$ starts to fall towards a minimum which corresponds to a second peculiar Daylight Factor value. It means that high values of Daylight Factor can provide high Daylight Autonomy and, at the same time, can decrease the risk of discomfort, but on the other hand, they can be associated with glare and excessive solar gains. The results highlighted that $\mathrm{DF}_{\mathrm{avg}}$ and DA values seem to be inappropriate to assess optimal lighting conditions without an analysis of non-uniformities. In fact, $\mathrm{DF}_{\mathrm{avg}}$ and $\mathrm{DA}$ values, generally considered good design targets for a given visual task, can be often associated to high levels of disorder (high non-uniformities). Although at this stage of the research, it is not yet possible to associate precise values of $H / H_{\max }$ to uncomfortable conditions, the tool has for sure the potential to assess appropriate lighting conditions for visual tasks while limiting the risk of discomfort and contributing to reducing energy consumption related to the often excessive use of artificial lighting. Correlations between $H / H_{\max }$ and measured discomfort indexes must be also investigated.

\section{NOMENCLATURE}
$D F$
Daylight Factor
[\%]
$D A$
Daylight Autonomy 


$\begin{array}{lll}L x & \text { Illuminance } & {[\mathrm{x}]} \\ H & \text { Entropy } & {[-]} \\ \Delta x & \text { Amplitude of interval } & {[-]} \\ P_{i} & \text { Probability of i-th signal } & {[-]} \\ H / H_{\max } & \text { Entropy parameter } & {[-]} \\ H / H_{\max -t} & \text { Time entropy parameter } & {[-]} \\ R & \text { Redundancy of signal } & {[-]}\end{array}$

\section{REFERENCES}

1. Galatioto, A., Leone, G., Milone, D., Pitruzzella S. and Franzitta, V., Indoor Environmental Quality Survey: A Brief Comparison between different Post Occupancy Evaluation Methods, Vol. 864-867, pp 1148-1152, 2014, http://dx.doi.org/10.4028/www.scientific.net/AMR.864-867.1148

2. Choi, J.-H., Loftness, V. and Aziz, A., Post-occupancy Evaluation of 20 Office Buildings as Basis for Future IEQ Standards and Guidelines, Energy and Buildings, Vol. 46, pp 167-175, 2012, http://dx.doi.org/10.1016/j.enbuild.2011.08.009

3. Nabil, A. and Mardaljevic, J., Useful Daylight Illuminance: A New Paradigm for Assessing Daylight in Buildings, Lighting Research and Technology, Vol. 37, pp 41-59, 2005, http://dx.doi.org/10.1191/1365782805li128oa

4. Konis, K., Evaluating Daylighting Effectiveness and Occupant Visual Comfort in a Side-lit Open-plan Office Building in San Francisco, California, Building and $\begin{array}{lllll}\text { Environment, } & \text { Vol. } & 59, & \text { 2013, }\end{array}$ http://dx.doi.org/10.1016/j.buildenv.2012.09.017

5. Reinhart, C. F. and Weissman, D. A., The Daylit Area - Correlating Architectural Student Assessments with Current and Emerging Daylight availability Metrics, Building and Environment, Vol. 50, pp 155-164, 2012, http://dx.doi.org/10.1016/j.buildenv.2011.10.024

6. Roger, Z., Daylight Metric Development using Daylight Autonomy Calculations in the Sensor Placement Optimization Tool, Development Report and Case Studies, Architectural Energy Corporation, Boulder, Colorado, USA, 2006.

7. Reinhart, C. F., Mardaljevic, J. and Rogers, Z., Dynamic Daylight Performance Metrics for Sustainable Building Design, LEUKOS - Journal of Illuminating Engineering Society of North America, Vol. 3, Issue 1, pp 7-31, 2006, http://dx.doi.org/10.1582/LEUKOS.2006.03.01.001

8. IESNA, Lighting Measurement e Spatial Daylight Autonomy (draft), NY: Illuminating Engineering Society of North America, New York, 2011.

9. Sherif, A. H., Sabry, H. M. and Gadelhak, M. I., The Impact of changing Solar Screen Rotation Angle and its Opening Aspect Ratios on Daylight Availability in Residential Desert Buildings, Solar Energy, Vol. 86, pp 3353-3363, 2012, http://dx.doi.org/10.1016/j.solener.2012.09.006

10.Shannon, C. E., A Mathematical Theory of Communication, Bell Syst. Tech. J., 1948.

11.Gray, R. M., Entropy and Information Theory, Internal Report, Information Systems Laboratory Electrical Engineering Department, Stanford University, NY, 1990, http://dx.doi.org/10.1007/978-1-4757-3982-4

12.Mahdavi, A. and Pal, V., Toward and Entropy-based Light Distribution Uniformity Indicator, Journal of the Illuminating Engineering Society, Vol. 28, pp 28-24, 1999, http://dx.doi.org/10.1080/00994480.1999.10748248

13.Georgescu-Roegen, N., The Entropy Law and the Economic Process, Harvard University Press, Cambridge, Massachusetts, 1971, http://dx.doi.org/10.4159/harvard.9780674281653

14.Cover, T. M. and Thomas, J. A., Elements of Information Theory, John Wiley and Sons, New York, 1991, http://dx.doi.org/10.1002/0471200611 
15.Hannan, M. and Freeman, J., Ecologia organizzativa, Per una teoria evoluzionistica dell'organizzazione, ETASLIBRI, Scienze umane, Milan, 1993.

16.Galatioto, A., Metodi e strumenti per la valutazione del comfort visivo, $\mathrm{PhD}$ Thesis, Dipartimento dell'Energia, Università degli Studi Palermo, Italy, 2012.

17.Barbera, G. and Butera, F. M., Diffusion of Innovative Agricultural Production Systems for Sustainable development of Small Islands: A Methodological Approach based on the Science of Complexity, Environmental Management, Vol. 16, pp 667-679, 1992, http://dx.doi.org/10.1007/BF02589020

18.http://daysim.ning.com, [Accessed:01-September-2014]

19.http://usa.autodesk.com/ecotect-analysis, [Accessed:01-September-2014]

20.Nabil, A. and Mardaljevic, J., Useful Daylight Illuminances: A Replacement for Daylight Factors, Energy and Buildings, Vol. 38, pp 905-913, 2006, http://dx.doi.org/10.1016/j.enbuild.2006.03.013 